\title{
An enigmatic translocation of the vertebrate primordial eye field
}

\author{
R. G. Loosemore ${ }^{1 *}$ D, S. D. Matthaei ${ }^{2}$ and T. C. Stanger ${ }^{2}$
}

\begin{abstract}
The primordial eye field of the vertebrate embryo is a single entity of retinal progenitor cells spanning the anterior neural plate before bifurcating to form bilateral optic vesicles. Here we review fate mapping data from zebrafish suggesting that prior to evagination of the optic vesicles the eye field may undergo a Maypole-plait migration of progenitor cells through the midline influenced by the anteriorly subducting diencephalon. Such an enigmatic translocation of scaffolding progenitors could have evolutionary significance if pointing, by way of homology, to an ancient mechanism for transition of the single eye field in chordates to contralateral eye fields in vertebrates.
\end{abstract}

Keywords: Contralaterality, Optic primordium, Primordial eye field, Optic chiasm, Inversation, Chiasmation, Cyclopean, Translocation, Retinal progenitor cells

\section{Background}

The vertebrate forebrain (prosencephalon), with its rostral telencephalon and caudal diencephalon, exhibits a cluster of four neuroanatomic anomalies in all species. The evolutionary origins of hemisphericity, contralaterality, optic chiasm, and retinal inversion, continue to defy plausible explanation. If the eye as a neural budding of the lightsensitive diencephalon is central to the development of all, exposure of the enigmatic processes that transitioned the single eye spot of chordates to the paired eyes of vertebrates might explain these anomalies. If cogent, this explanation would clarify embryological homologies, enhancing potential developmental and medical implications.

Early in vertebrate gastrulation the neural plate is elongated by convergent extension [65] where laterally placed progenitor cells move toward the midline, intercalating into the midline $[36,37,69]$. This process of neurulation, which characterises the tubular folding of most of the neural plate to form the neural tube $[9,24]$ is a defining developmental process in vertebrates. The distinctive anterior of the neural plate (ANP) where the eye and

\footnotetext{
* Correspondence: guylo50@hotmail.com

${ }^{1}$ Maclean District Hospital, Union St, Maclean, NSW 2463, Australia

Full list of author information is available at the end of the article
}

forebrain develop, does not undergo this same neurulation as once thought $[3,23]$. Its development begins earlier than neurulation, largely as a single coherent field of retinal progenitor cells (RPCs) that contracts from an early broad field to then bifurcate and evaginate to form bilateral optic vesicles $[1,2,4,15,23,31,33,46,53,64,76,80]$.

Contraction of the eye field (EF) follows an initial period of expansion characterised by proliferation of RPCs as gastrulation proceeds, with RPCs and their progeny migrating individually [71]. This contraction involves a 'roll over' migration of lateral RPCs over medial RPCs toward the midline [15, 64]. However, at the midline where RPCs are then observed to dive ventrally before apparently moving back laterally toward the periphery, there is condensed mixing of RPCs where some are lost to the contralateral EF $[15,64]$. Further clarification is required of this moment of freneticism where large numbers of proliferated cells are condensed into a narrow midline field in a crush that briefly brings together cells that were furthest apart on opposite sides of the EF $[15,64]$. This peak moment of midline invasion puts pressures on observation, decreasing confidence in the limits of imaging technologies and tests our abilities to observe precise continuity in single-cell 
lineages. What numbers and percentages of cells, for example, cross the midline and fail to return to their side of origin?

Historically, the conception that the EF of vertebrate embryos might actually be single before resolving to bilateral optic vesicles was intimately related to the discovery of midline crossings of RPCs $[76,80]$. This discovery was inspired by the recognition that the human fetal abnormality alobar holoprosencephaly (cyclopia) is common across all vertebrate species $[28,45]$ and that the anomaly probably results from failure of a single EF to divide $[5,14$, $28,51,76]$. The most convincing evidence supporting this hypothesis came from a series of fate mapping studies late last century that employed highly specific individual celllabelling techniques $[2,33,76,80]$ revealing that Nodaldeficient mutants fail to separate the EF, thereby exhibiting cyclopia $[17,26,27,66]$.

In wild-type zebrafish however, some RPCs and their progeny translocated across the midline to the contralateral optic vesicle, an observation that was used as primary evidence to argue that the EF was therefore singular prior to bifurcation $[2,76,80]$, a view that is now the consensus. Another unrelated mixing of cells across the midline takes place in the remaining caudal aspect of the neural plate where a process called 'mirrorsymmetric divisions' [74] create polar opposite clones which migrate to either side of the midline triggering formation of both neural rod midline and lumen.

\section{Quantifying the translocation}

In 1995 a landmark single-cell fate mapping study of the EF in the zebrafish Danio rerio, while noting substantial translocation, did not explore any further significance of this translocation because of the more fundamental question at that time relating to whether cyclopia was a consequence of a single EF failing to divide or of two eye fields merging to become one. The incidental finding in this study that RPCs crossed the midline helped establish the general case for a prior single EF [80] but otherwise remained unexplored.

Four years later the most specific fate mapping study ever performed for single cell-lineage in the zebrafish EF was published just prior to the abandonment of this very specific technique in favour of mass-cell microscopy [76]. This study presented a detailed set of data that allows significant interpretation beyond the aims of the study itself and is here condensed and adapted in Fig. 1. Essentially, to show that the EF was a homogenous single set of RPCs prior to the anterior movement of the diencephalon that was thought to bifurcate the EF, single RPCs were injected with tracer dye at $80 \%$ epiboly and observed for fates at tailbud stage by sectioning the

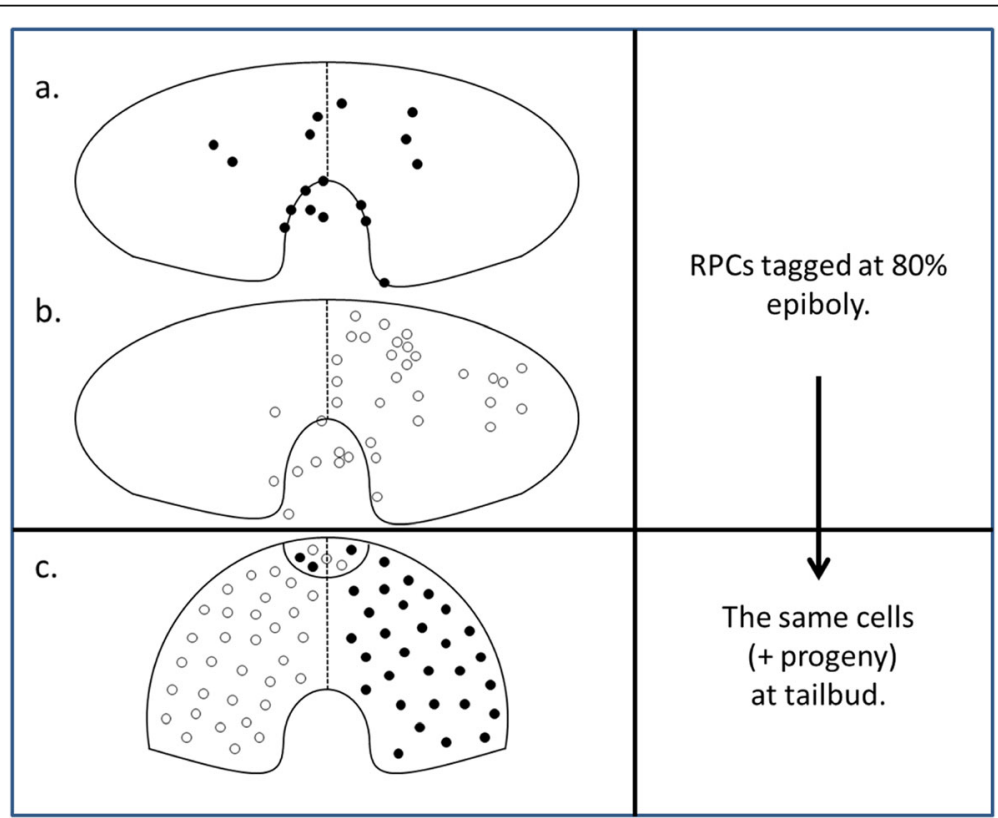

Fig. 1 a, b, c Evidence for a translocating Optic Primordium. Cartoons adapted from previously published data [76]. Dorsal views of the ANP of wild-type zebrafish embryos (Danio rerio). Anterior to the top. The outline shows the limit of the EF (and Opl gene expression zone) and posterior indentation by the diencephalic 'mar' expression border subducting anteriorly. $\mathbf{a}$, b Single RPCs were randomly labelled with lineage tracer (a mixture of rhodamine dextran and fluorescein dextran) at 80\% epiboly. RPCs that matured in the right optic vesicle (c) are drawn here as dark circles, those that matured in the left optic vesicle (c) as clear circles. At 80\% epiboly up to 30\% of RPCs may have crossed the midline while the remaining 70\% do so by tailbud. c at tailbud all RPCs (and progeny) are accounted for in optic vesicles as shown including within the presumptive optic stalk/chiasm (Maypole distribution). Cell numbers and locations in cartoon (c) are not intended to be precise 
specimen. This was done repeatedly, one cell per specimen, and a control specimen, using a grid to plot positions of each cell labelled. The finding that a significant quantity of RPCs mingled across the midline to contribute to the contralateral optic vesicle was presented as support for the proposition that the EF was initially single but further significance was again not explored.

Closer scrutiny of the data as presented further shows that $70 \%$ of the RPCs labelled at $80 \%$ epiboly later crossed the midline to the contralateral optic vesicle and that some of the remaining 30\% may already have crossed due to their proximity to the midline at $80 \%$ epiboly. Two outlying cells were omitted from our calculations as they were labelled as ending up on both sides. Another cell was excluded as it was located in the optic stalk. This left our total count at 53 remaining cells injected, with some minor uncertainty where red/blue labelling of a few cells in the original figure failed to clearly distinguish whether two single cells overlapped each other or a single cell contributed to progeny on both sides at tailbud. Our decision to include or exclude these few cells was based on a tenfold magnification of the figure.

This proximity to the midline of the $30 \%$ suggests that if the cells had been injected earlier, say at $75 \%$ epiboly ( $8 \mathrm{~h}$ post fertilization - hpf) rather than at $80 \%$ epiboly, it is possible that more RPCs might have been found to originate on the side contralateral to their destinations. This would be consistent with a primordium that begins translocation across the midline prior to $80 \%$ epiboly, translocating up to $30 \%$ of its constituent cells by $80 \%$ epiboly, to be fully translocated at tailbud. (For stages of embryonic development see [38]).

The more recent studies on migration of RPCs [15, 64], rather than tracing a single cell and its clones, employed confocal time-lapse mass-cell microscopy techniques offering greater morphological specificity in terms of 3 and 4-dimensional organogenesis and stunning visual displays. These studies, in zebrafish and medaka fish respectively, unlike the previous study showed only minimal crossing of the midline by RPCs. However, it is not certain that these studies approximate the single-cell specificity of the earlier studies, especially at moments of intense congested agitation of cells such as at the midline during contraction of the EF. Compounding these uncertainties is the absence of verifiable quantification and dependence on visual time-lapse reconstructions from digital algorithms that are somewhat impervious to critical scrutiny.

Despite these limitations these studies made major advances, showing as never before the complex shapechanging over time of the developing EF. In particular they showed that prior to neurulation the EF begins posterior contraction toward a focus at the anterior tip of the hypothalamic anlagen (ventral diencephalon), the anterior limit of the neural keel (Fig. 2). As the keel subducts anteriorly beneath the EF posterior RPCs are drawn deep and anteriorly at the midline forming a transient whorl where RPCs from both sides move together along the midline. This focussed dynamic whorl is itself observed to advance anteriorly to eventually resolve at the site of the presumptive optic stalks as the optic vesicles evaginate [15].

The uncertainties discussed earlier as to whether these studies were capable of detecting RPCs crossing the midline appeared to be circumvented in a later study that employed Kaeda, a photoconvertible fluorescent protein introduced to the cytoplasm of the RPCs in zebrafish [32]. This was done to identify if any RPCs intercalate across the midline of the EF in the c-zipper fashion of the more caudal neural plate $[7,8,22,39,74]$. One half of the cells of the EF were converted from
B.

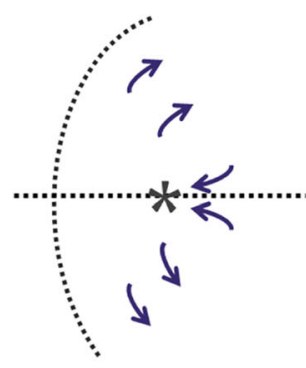

$10 \mathrm{hpf}$.
D.

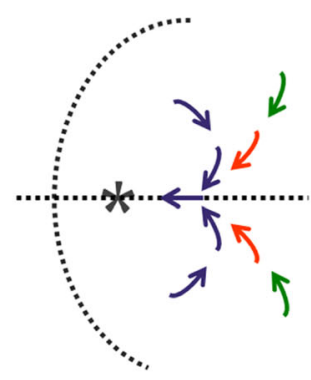

$12 \mathrm{hpf}$.
K/L.

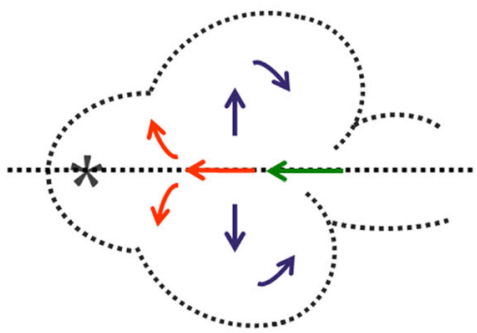

15 hpf.

Fig. 2 Three stages $(B, D, K$ to $L$ ) of contraction and evagination of the zebrafish EF where the subducting neural keel is followed by a midline whorl of mixed cells from both sides. Adapted from Fig. 1. of [15]. Dorsal views, anterior to the left. Arrows show migration of progenitor cells: blue (eye field), red (optic stalk), green (diencephalon). Asterisks indicate anterior tip of neural keel formation (hypothalamus). HPF, hours post fertilization 
fluorescent green to red by UV illumination at commencement of imaging at $10.5 \mathrm{hpf}$. In this time-lapse series it was found that midline crossing of cells between $10.5 \mathrm{hpf}$ and $13 \mathrm{hpf}$ was rare.

This finding, however, is confounded by further uncertainties related to the timing of the observation period designed only to capture late cell developments rather than early migrations. The movie showing the photoconversion [32] depicts a single confocal plane, a transverse two-dimensional slice (plus time) through the developing forebrain beginning at $10.5 \mathrm{hpf}$. Timing is critical for our purposes because of the early anterior movement along the midline of the advancing whorl of RPCs. Contraction of the EF begins posteriorally at $8 \mathrm{hpf}$, anterior subduction of the hypothalamus immediately following [15]. Not only is the $10.5 \mathrm{hpf}$ commencement of the movie two thirds through subduction late in this process, the transverse positioning of the confocal plane appears to be directed more posteriorly than anteriorly where contraction of the EF resolves early.

In summary, while the early 'gold standard' single-cell fate mapping studies point convincingly to significant midline translocation of RPCs, later mass-cell microscopy studies, while failing to confirm this significance, point to an intense transient mixing of RPCs at the midline of the posterior EF in a whorl which advances in tandem with the subducting hypothalamus. Behind its anterior advancement the EF is bisected, the whorl behaving like an advancing conduit, possibly for contralateral translocation of RPCs.

To reformulate: Based on presently established data from the most specific fate mapping study performed to date, at least $70 \%$ of RPCs that specify the EF domain and its future architecture will contribute to the contralateral optic vesicle. For this to happen, the RPCs that cross the midline must do so during peak contraction of the EF where they all appear to progressively mingle and dive ventrally in a whorl of congested midline hypermobility that advances from the posterior EF to the anterior $\mathrm{EF}$, the latter being the site of the presumptive optic stalks. It is likely therefore, that the subsequent lateral movement of ventral RPCs previously thought to be of those returning to the ipsilateral EF from the midline between 8 and $12 \mathrm{hpf}[15,64]$ is in fact movement of RPCs that have crossed the midline from the contralateral EF via this dynamic conduit as the EF bisects.

\section{Eye field morphology in zebrafish}

The mechanisms that drive the distinctive early development of the ANP, particularly the EF and optic chiasm, remain poorly analysed [23]. This is despite a more comprehensive understanding of the processes of eye and retinal development. The EF folds and bifurcates in a complex way, especially at the midline, but ultimately forms two pouches of RPCs that evaginate from the lateral epithelial walls of the diencephalon to give rise to the optic vesicles, the primordia of the eyes [32]. These evaginations are the consequence of RPCs migrating away from the midline after having converged to mix at the midline. While laterally moving cells have been shown to acquire either core or marginal attributes where mesenchymal core cells and marginal epithelial cells later undergo elongation and intercalation [32] the more intricate processes at the midline where the incipient optic chiasm forms are poorly defined.

During evagination the EF becomes patterned to give rise to a proximal future stalk domain and also a combined distal retinal pigment epithelium (RPE)-neural retinal (NR) domain $[18,29]$. RPCs destined to form the eye continue to evaginate laterally toward the surface ectoderm [32, 41, 64] where, on contact, the optic vesicle invaginates to form the double-layered optic cup. The eye forms through a series of coordinated interactions between tissues of different origins: the retinal neuroepithelium, non-neural surface ectoderm, and a loose array of cells arising from both neural crest and mesoderm [19]. The inner layer of the optic cup is composed of prospective neural retinal cells and the outer layer composed of the primordium of the RPE $[6,19,54]$. The invagination process, which is associated with the development of the lens, leads to the formation of a transient opening along the ventral retina and optic stalk termed the choroid, or optic, fissure [68] which later fuses.

After positioning in the neural retina RPCs begin differentiating either to retinal ganglion cells (RGCs), horizontal cells, amacrine cells, cone cells, Müller cells, rod photoreceptors, or bipolar cells. While there are different stochastic models for the ordering of this process [44] the primacy of the RGC is well recognised. Once differentiated, RGCs begin a 'retrograde axonal outreach' back toward the midline, continuing centrally to cross the midline at the incipient optic chiasm before reaching the targeted contralateral ventral diencephalon.

\section{A prototypic optic chiasm}

A general characteristic of vertebrates is the possession of bilateral eyes and an optic chiasm that connects the retinas to the forebrain. At the optic chiasm the left and right optic nerves cross, often completely, but in some groups of vertebrates particularly mammals, a fraction of the nerves remain uncrossed to form a semidecussation. In the groups that mostly cross completely such as teleost fish, the decussation is mostly uncomplicated, left over right or right over left [34, 35]. The remainder of these groups have either a meshed chiasm or, as in the more primitive species of teleosts, a fused chiasm [57]. In the agnathan lamprey the mostly 
decussated chiasm contains a small ipsilateral component [11] and in the agnathan hagfish the chiasm is hidden within the hypothalamus [40]. While we cannot know the true structure of the optic chiasm in the first vertebrates the predominance of an uncomplicated complete decussation in most fish [79] allows that a simple crossing of one optic nerve over the other might be primitive for vertebrates. If so, the modern teleost might be a reasonable proxy for ascertaining primitive homologies.

Proximal prevertebrate chordates however, such as cephalochordates and urochordates, possess neither bilateral chambered eyes nor an optic chiasm. Cephalochordates though, possess a single medial eyespot which is now confidently regarded as the homologue of the vertebrate lateral eyes $[43,77]$. Unfortunately, due to a paucity of both transitional fossils and extant progeny of transitional craniates, the mechanisms driving the evolutionary change from a single medial eye spot to bilateral eyes with a chiasm remain enigmatic.

\section{Toward a testable hypothesis for retino-forebrain evolution}

While contralateral translocation of RPCs in the primordial eye field of vertebrates might seem counterintuitive, as well as difficult to detect with time-lapse digital algorithms, there are historical precedents according to the Inversion Hypothesis [47-49] that suggest it may be imperative. This hypothesis postulates an initial 2-phase evolution of the eye and forebrain (retino-forebrain) in ancestral vertebrates punctuated by an ancient genome duplication resulting in a contralateral hemispherical forebrain and optic chiasm:

1. Inversation - the contralateralising of the nonhemispherical retino-forebrain of chordates by increasing selection of contralateral visual inputs due to maturation of the cyclopean eye. This theoretical framework, developed and published previously [48], is built particularly on the work of both Lacalli $[42,43]$ who showed that the single eye of the extant prevertebrate amphioxus (Branchiostoma) is homologous to the lateral eyes of vertebrates, and Nilsson and Pelger [59] who showed how the evolution of the primitive chambered eyes could have happened quickly by deepening of the retinal pits (Figs. 3 and 4).

2. Chiasmation - the later duplication of the single eye by a disruptive 3-vector developmental process; translocation, bifurcation, and invagination of the cyclopean eye field in craniates. This theoretical framework is constructed de novo as the most parsimonious way to duplicate a cyclopean eye while conserving the established contralateral retinofugal infrastructure of the primitive vertebrate forebrain (Figs. 4, 5 and 6). This event would likely have been triggered by new genes such as the Nodalrelated ligand 'cyclops' (previously called Ndr2) following the genome duplication, acting homologously to today where in early embryogenesis 'cyclops' induces formation of bilateral optic vesicles from a single optic primordium $[6,25,28,63,66,76]$. In this way "anterior expansion of a CNS ventral midline signaling system, involving cells specified by the 'cyclops' gene and increasing the size and complexity of the brain, might have been a key step during early evolution of vertebrates" [28].

Such a critical ancient chiasmation event, contributing as it would to the predatory power of the first vertebrates, should be identifiable in the very early morphological development of all vertebrate embryos today whereby:

- the EF should be single.

- it should translocate prior to bifurcation such that most RPCs (depending on the species) should cross the midline to mature in the contralateral optic vesicle.

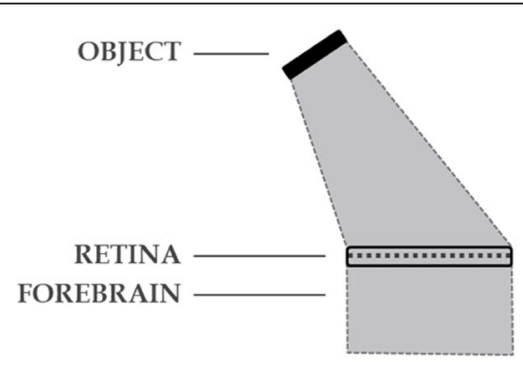

1

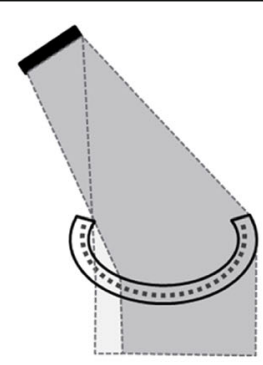

2

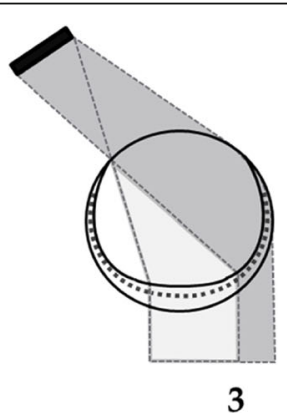

3

Fig. 3 Inversation in prevertebrates. Progressive maturation of the cyclopean eye $(1,2,3)$ by deepening of the retinal pit, favours contralateral inputs of light to the retina (dark shading) by exclusion of inputs ipsilaterally and centrally. This lateralization is maintained in the developing adnexal diencephalon. For further exposition of this concept see Loosemore [48] 


\section{HOX CLUSTER \\ (CEPHALOCHORDATES)}

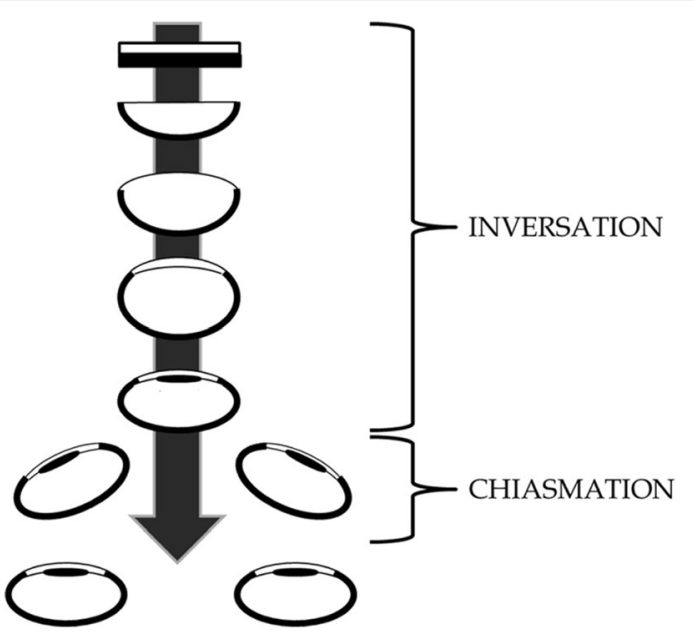

Fig. 4 A genome duplication period coincides with duplication of the eye triggering new cyclopia-nulling genes such as 'cyclops' to initiate eye duplication. Arrow shows progression of time and eye maturation

- by this process the incipient optic chiasm should form and the retina invert.

- bifurcation of the EF should require the action of cyclopia-nulling genes which, if deactivated, will result in cyclopia.

Much of the above has been demonstrated experimentally in varying degrees in vertebrates such as zebrafish including now the apparent translocation of the EF leading to formation of the optic chiasm, the critical element of the proposed chiasmation process. As techniques for the observation and measurement of the origin and migration of embryonic cells (cell lineage) continue to advance we should expect techniques such as light sheet microscopy to eventually confirm and expand the findings already catalogued by past 'gold standard' techniques. If so, the finding that at least $70 \%$ of RPCs cross the midline to the contralateral optic vesicle should support the above hypothesis offering insights for:

- the single EF of vertebrate embryos (cyclopia in ancestral craniates).

- the contralaterality of the forebrain (Inversation by cyclopean eye maturation).

- the historical 'point-of-origin' of cyclopia-nulling genes (the Chiasmation event).

- the 'mechanism-of-origin' of the optic chiasm by Maypoling translocation of the EF (Chiasmation stage 1).

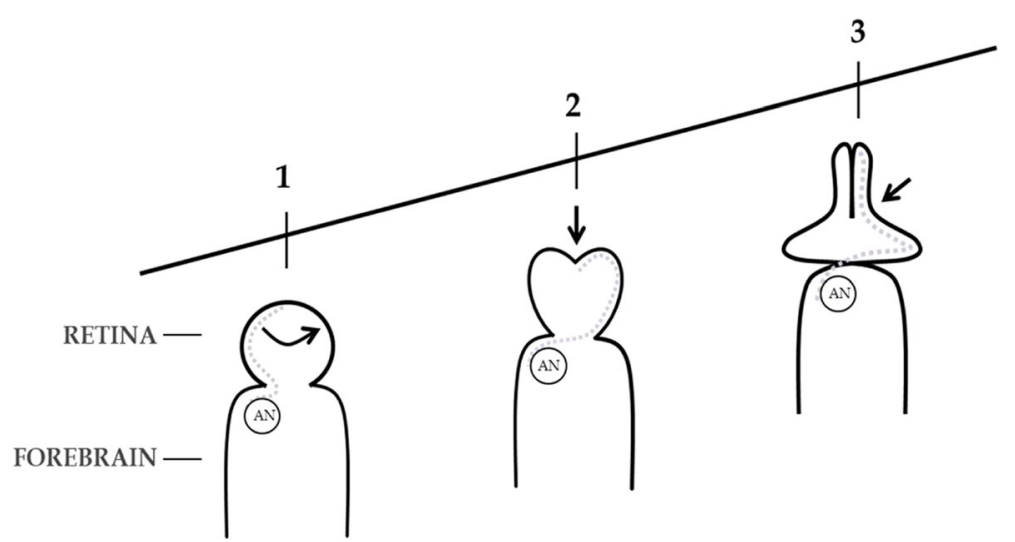

Fig. 5 Chiasmation in the craniate embryo. Conceptual representation of EF duplication by the simultaneous 3-vector process: translocation, bifurcation, and invagination, resulting in bilateral eyes with retinal inversion and a chiasm. Anterior to the top. Dorsal representation. Arrows show vectors of change with vector 2 to be interpreted as midline rather than anterior. Dotted lines show the change in migration of RPCS across the midline. Final pathways reflect known retinofugal pathways to the putative anterior nucleus (AN) of the dorsal thalamus in extant primitive species 


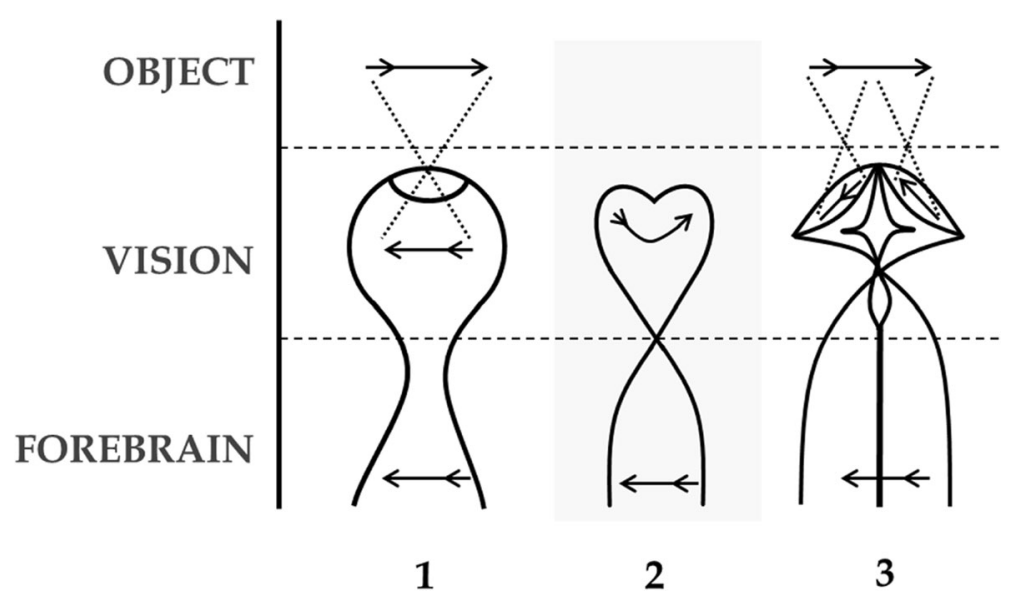

Fig. 6 Eye duplication by chiasmation in craniates, with retinotopic conservation in the diencephalon. Contralateral forebrain infrastructure is conserved despite radical changes to retinal structures. Arrows show orientation of visual images. Anterior to the top. Dorsal representations. No 2 represents a conceptual (not actual) link between two adult phylogenies

- the origin of eye duplication and forebrain hemisphericity (Chiasmation stage 2).

- the mechanism for inversion of the vertebrate retina (Chiasmation stage 3).

\section{Discussion}

The suggestion that RPCs translocate en masse across the midline and the inference here that this might relate to the formation of the optic chiasm will be discussed below by way of question and response followed by a brief comment on the more peripheral topic of developmental retinal inversion.

\section{Should translocation of RPCs predetermine formation of the optic chiasm, and if so, by what mechanism might translocation and decussation be coupled?}

The novel disruptive reorganisation of the retinoforebrain by the proposed chiasmation event is predicated on the introduction of new genetic, chemotactic, and mechanistic triggers, that while not yet fully elucidated are hypothesised to lead to the formation of the optic chiasm. However, the two distinct processes of translocation and decussation would appear to be coupled, not exactly in time, but almost in place, the former determining the latter.

While the sequential processes in the embryological development of the vertebrate optic vesicle, optic cup and retina are now quite well understood, the formative chiasmatic processes remain to be adequately described. This might, in part, be due to our incomplete understanding of the cellular milieu at the midline as the neural keel subducts anteriorly beneath the bifurcating EF to form bilateral incipient optic stalks and optic vesicles.
EF bifurcation follows anterior migration of the prechordal plate $[46,61]$ to move Nodal and hedgehog-secreting cells forward beneath the medial ANP. A consequent midline anteroventral 'shearing' process by the ventral diencephalon on the posterior EF begins separating the EF by initiating convergent migration of RPCs anteroventrally along, and possibly across, the midline of the EF. Our proposed major translocation of RPCs across the midline would appear during resolution of bifurcation to contribute to an early scaffold for the incipient chiasm by deposition of 'remnant' midline cells that might later cue RGC axons to decussate back across the midline. This idea of an early template for later growth of retinal axons was mooted by Easter et al. [13] and Sretavan et al. [72]. The latter claimed that in addition to neuroepithelial cells and glial cells, the presumptive chiasm contained a population of early generated neurons that express cell surface molecules capable of influencing retinal axon growth. According to Deiner and Sretavan [12], preceding arrival of RGC axons from the retina a partial incipient chiasm is in place at the ventral diencephalon (in the mouse embryo) which influences the completion of the chiasm. This principle is echoed by Ivanovitch et al. [32] who observed that the successful formation of the optic vesicles from embryonic stem cells is dependent upon a Laminin-rich Matrigel, a matrix protein that might provide an essential scaffold on which EF cells can organize.

Growth of RGCs begins in the retina and progresses centrally toward the presumptive optic chiasm after commitment of some of the multipotent progenitors to RGC fate. This happens during, or shortly after, the terminal cell division [56, 60, 62, 78]. Once RGC axons exit the eye they grow amongst the intrafascicular glial cells of the optic nerve $[16,70]$ with pioneer axons from the 
dorso-central retina navigating into the optic stalk ultimately traversing the midline to complete the formation of the optic chiasm.

As the RGC axons enter the midline region they encounter incipient optic chiasm neurons along its posterior boundary organized into an inverted V-shaped array $[52,55]$. These neurons express the cell surface protein CD44 [72] and the SSEA-1 epitope [30, 52]. RGC axons grow through the chiasm region along the anterior edge of the CD44/SSEA-positive neuronal population which, in turn, facilitates the permissive decussation of RGC axons [52]. Experimental evidence also shows that these neurons are required for RGC axons to cross the chiasm midline [73].

\section{Does homology constrain developmental retinofugal options thereby necessitating an optic chiasm?}

Map-like representation of sensory information is an evolutionarily conserved principle of brain organisation and function [50]. It follows that a species of pregenome-duplication craniate would have had its forebrain retinotopy conserved in a post-duplication generation despite disruptive changes impacting the more malleable peripheral visual apparatus. An early retinal arrangement in cyclopean craniates that had achieved a dominant level of contralateral diencephalic representation should, if the retina was to be suddenly reorganised, have had the established retinotopy conserved in order that the species survived. Even after major disruption of the single median retina where each half resituated to the opposite side, this homologous constraint would have ensured that the relevant RGC axons crossed the midline to maintain retinotopic authenticity. This might feasibly have involved deposition and early differentiation of proximal midline progenitors at the site of the incipient optic chiasm following bifurcation of the eye field.

\section{Retinal inversion}

The classic revision by Sarnat and Netsky [67] of Polyak's 1957 theory of the development of the eye which convincingly described a very plausible pathway for development of the inverted retina no longer appears to fully satisfy the observations this century of a more complex unfolding of the ANP (For history of this theory see also [10]). While explanation for the inverted retina should continue to follow stepwise from the early neurulation of the ANP, the emerging understanding of the complex geometric unfolding of the single primordium should now constrain our options for describing the ontogenesis of retinal inversion.

\section{Conclusion}

With expert opinion now shifting away from the traditional view that vertebrate eyes developed from an early intermediate bilateral stage exemplified by the rudimentary eyes in the extant hagfish agnathan [20] and toward a view favouring single eye duplication in protovertebrates $[21,58,77]$ we await further palaeontological consideration like that of van der Brugghen [75] as to whether the earliest vertebrate fossils might now be seen to possess a frontal median eye. If such a finding transpires, Maypole-translocation of the EF in the vertebrate embryo would enhance the view that Inversation and Chiasmation might well inform the enigmatic intermediate processes for early vertebrate retino-forebrain evolution.

\section{Abbreviations}

ANP: Anterior neural plate; EF: Primordial eye field; NR: Neural retina; $\mathrm{RPC}$ : Retinal progenitor cell; RPE: Retinal pigmented epithelium

\section{Acknowledgements \\ We thank Philipp Keller (Professor at Howard Hughes Medical Institute, USA) for the generous loan of dynamic cell-lineage data, Ethan Scott (Professor at University of Queensland, Australia) for technical advice, and Philippe Janvier (Fellow of the French Academy of Sciences, France) for advice and encour- agement over many years.}

\section{Authors' contributions}

R.G.L. contributed the text. S.D.M. and T.C.S. contributed technical support and figures. All authors have read and approved the manuscript.

Funding

Nil.

Availability of data and materials

Not applicable.

Ethics approval

Not applicable.

Consent for publication

Not applicable.

Competing interests

Nil.

Author details

${ }^{1}$ Maclean District Hospital, Union St, Maclean, NSW 2463, Australia. ${ }^{2}$ Maclean District Hospital, Maclean, Australia.

Received: 17 July 2019 Accepted: 17 September 2020

Published online: 02 October 2020

References

1. Adelmann HB. The problem of cyclopia, Pt. 1. Quart Rev Biol. 1936;11:161-82.

2. Ballard WA. A new fate map for 'Salmo gairdneri'. J Exp Zool. 1973;184:49-73.

3. Bazin-Lopez N, Valdivia LE, Wilson SW, Gestr G. Watching eyes take shape. Curr Opin Genet Dev. 2015;32:73-9. https://doi.org/10.1016/j.gde.2015.02.004.

4. Cavodeassi F. Dynamic tissue rearrangements during vertebrate eye morphogenesis: Insights from fish models. J Dev Biol. 2018;6(1):4. https:// doi.org/10.3390/jdb6010004

5. Chiang $C$, Litingtung $Y$, Lee E, Young $K E$, Corden $J$, Westphal $H$, et al. Cyclopia and defective axial patterning in mice lacking sonic hedgehog gene function. Nature. 1996;383:407-13. https://doi.org/10.1038/383407a0.

6. Chow RL, Lang RA. Early eye development in vertebrates. Annu Rev Cell Dev Biol. 2001;17:255-96. https://doi.org/10.1146/annurev.cellbio.17.1.255. 
7. Ciruna B, Jenny A, Lee D, Mlodzik M, Schier AF. Planar cell polarity signalling couples cell division and morphogenesis during neurulation. Nature. 2006; 439:220-4. https://doi.org/10.1038/nature04375.

8. Compagnon J, Heisenberg C-P. Neurulation: coordinating cell polarisation and lumen formation. EMBO J. 2012;32:1-3. https://doi.org/10.1038/emboj. 2012.325 .

9. Copp AJ, Greene NDE, Murdoch JN. The genetic basis of mammalian neurulation. Nat Rev Genet. 2003;4:784-93. https://doi.org/10.1038/nrg1181.

10. Cronly-Dillon JR, Gregory RL. Origin of invertebrate and vertebrate eyes. (Chapter 2): Vision and visual dysfunction (2): Evolution of the eye and visual system. London: Macmillan Press Ltd; 1991. p. 2-42.

11. De Miguel E, Rodicio MC, Anadon R. Organization of the visual system in larval lampreys: an HRP study. J Comp Neurol. 1990;302(3):529-42.

12. Deiner MS, Sretavan DW. Altered midline axon pathways and ectopic neurons in the developing hypothalamus of netrin-1- and DCC-deficient mice. J Neurosci. 1999;19(22):9900-12. https://doi.org/10.1523/JNEUROSCl. 19-22-09900.

13. Easter SS, Ross LS, Frankfurter A. Initial tract formation in the mouse brain. J Neurosci. 1993:13:285-99.

14. Ekker SC, Ungar AR, Greenstein P, von Kessler DP, Porter JA, Moon RT, et al. Patterning activities of vertebrate hedgehog proteins in the developing eye and brain. Curr.Biol. 1995;5:944-55. https://doi.org/10.1016/S0960-9822(95)00185-0.

15. England SJ, Blanchard GB, Mahadevan L, Adams RJ. A dynamic fate map of the forebrain shows how vertebrate eyes form and explains two causes of cyclopia. Development. 2006;133:4613-7. https://doi.org/10.1242/dev.02678.

16. Erskine L, Hererra E. Connecting the retina to the brain. ASN Neurol. 2014; 6(6):Oct-Dec. https://doi.org/10.1177/1759091414562107.

17. Feldman B, Gates MA, Egan ES, Dougan ST, Rennebeck G, Sirotkin HI, et al. Zebrafish organiser development and germ-layer formation require nodalrelated signals. Nature. 1998;395:181-5. https://doi.org/10.1038/26013.

18. Fuhrman S, Zou C, Levine EM. Retinal pigment epithelium development, plasticity, and tissue homeostasis. Exp Eye Res. 2014;123:141-50. https://doi. org/10.1016/j.exer.2013.09.003.

19. Fuhrmann S. Eye morphogenesis and patterning of the optic vesicle. Curr Top Dev Biol. 2010;93:61-84. https://doi.org/10.1016/B978-0-12-385044-7.00003-5.

20. Gabbott S, Donoghue PCJ, Sansom RS, Vinther J, Dolocan A, Purnell MA Pigmented anatomy in carboniferous cyclostomes and the evolution of the vertebrate eye. Proc Royal Soc B Biol Sci. 2016;283(1836):20161151. https:// doi.org/10.1098/rspb2016.1151.

21. Gee H. Across the bridge: understanding the origins of vertebrates. Chicago: University of Chicago Press; 2018.

22. Geldmacher-Voss B, Reugels AM, Pauls S, Campos-Ortego JA. A 90-degree rotation of the mitotic spindle changes the orientation of mitoses of zebrafish neuroepithelial cells. Development. 2003;130:3767-80. https://doi. org/10.1242/dev.00603.

23. Giger FA, Houart $C$. The birth of the eye vesicle: When fate decision equals morphogenesis. Front Neurosci. 2018;12:87. https://doi.org/10.3389/fnins. 2018.00087

24. Greene NDE, Copp AJ. Development of the vertebrate central nervous system: formation of the neural tube. Prenat Diagn. 2009;29:303-11. https:// doi.org/10.1002/pd.2206

25. Gripp KW, Wotton D, Edwards MC, Roessler E, Ades L, Meinecke P, RichieriCosta A, Zackai EH, Massague J, Muenke M, et al. Mutations in TGIF cause holoprosencephaly and link NODAL signaling to human neural axis determination. Nat Genet. 2000;25:205-8. https://doi.org/10.1038/76074.

26. Gritsman K, Zhang J, Cheng S, Heckscher E, Talbot WS, Schier AF. The EGFCFC protein one-eyed pinhead is essential for nodal signalling. Cell. 1999;97: 121-32. https://doi.org/10.1016/S0092-8674(00)80720-5.

27. Hatta K, Kimmel CB, Ho RK, Walker C. The cyclops mutation blocks specification of the floor plate of the zebrafish central nervous system. Nature. 1991;350:339-41. https://doi.org/10.1038/350339a0.

28. Hatta K, Puschel AW, Kimmel CB. Midline signaling in the primordium of the zebrafish anterior central nervous system. Proc Natl Acad Sci U S A. 1994;91:2061-5.

29. Heavner W, Pevney L. Eye development and retinogenesis. Cold Spring Harb Perspect Biol. 2012;4:a008391. https://doi.org/10.1101/cshperspect. a008391.

30. Hererra E, Garcia-Frivola C. Genetics and development of the optic chiasm. Front Biosci. 2008:13:1646-53. https://doi.org/10.2741/2788.

31. Hirose $G$, Jacobson M. Clonal organization of the central nervous system of the frog. I. Clones stemming from individual blastomeres of the 16-cell and earlier stages. Dev Biol. 1979;71:191-202.
32. Ivanovitch K, Cavodeassi F, Wilson SW. Precocious acquisition of neuroepithelial character in the eye field underlies the onset of eye morphogenesis. Dev Cell. 2013;27:293-305. https://doi.org/10.1016/j.devcel. 2013.09.023.

33. Jacobson $\mathrm{M}$, Hirose $\mathrm{G}$. Origin of the retina from both sides of the embryonic brain: a contribution to the problem of crossing at the optic chiasma. Science. 1978;202:637-9.

34. Jeffery G. Architecture of the optic chiasm and the mechanisms that sculpt its development. Physiol Rev. 2001;81:1393-414. https://doi.org/10.1152/ physrev.2001.81.4.1393.

35. Jeffery $G$, Erskine L. Variations in the architecture and development of the vertebrate optic chiasm. Prog Retin Eye Res. 2005;24:721-53. https://doi.org/ 10.1016/j.preteyeres.2005.04.005.

36. Keller R, Davidson L, Edlund A, Elul T, Ezin M, Shook D, Skoglund P. Mechanisms of convergence and extension by cell intercalation. Phil Trans Royal Soc London B: Biol Sci. 2000;355:897-922. https://doi.org/10.1098/rstb. 2000.0626.

37. Keller R, Shih J, Sater AK, Moreno C. Planar induction of convergence and extension of the neural plate by the organiser of Xenopus. Dev Dyn. 1992; 193:218-34. https://doi.org/10.1002/aja.1001930303.

38. Kimmel CB, Ballard WW, Kimmel SR, Ullman B, Schilling TF. Stages of embryonic development of the zebrafish. Dev Dyn. 1995;203:253-310.

39. Kimmel CB, Warga RM, Kane DA. Cell cycles and clonal strings during formation of the zebrafish central nervous system. Development. 1994;120:265-76.

40. Kusunoki T, Amemiya F. Retinal projections in the hagfish, Eptatretus burgeri. Brain Res. 1983:262:295-8.

41. Kwan KM, et al. A complex choreography of cell movements shapes the vertebrate eye. Development. 2012;139(2):359-72. https://doi.org/10.1242/ dev.071407.

42. Lacalli TC. Apical orgins, epithelial domains, and the origin of the chordate central nervous system. Amer Zool. 1994;34:533-41. https://doi.org/10.1093/ icb/34.4.533.

43. Lacalli TC. Frontal eye circuitry, rostral sensory pathways and brain organization in amphioxus larvae: evidence from 3D reconstructions. Phil Trans R Soc London B. 1996;351:243-63. https://doi.org/10.1098/rstb.1996.0022.

44. Lamb TD, Collin SP, Pugh EN Jr. Evolution of the vertebrate eye: opsins, photoreceptors, retina and eye cup. Nat Rev Neurosci. 2007;8:960-76. https://doi.org/10.1038/nrn2283.

45. Leroi A. Mutants: on the form, varieties and errors of the human body. London: Harper Perennial; 2003.

46. Li H, Tierney G, Wen L, Wu JY, Rao Y. A single morphogenetic field gives rise to two retinal primordia under the influence of the prechordal plate. Development. 1997;124:603-15.

47. Loosemore RG. The inversion hypothesis: a novel explanation for the contralaterality of the human brain. Biosci Hypotheses. 2009;2(6):375-82. https://doi.org/10.1016/j.bihy.2009.08.001.

48. Loosemore RG. The evolution of forebrain contralaterality as a response to eye development: the path of least resistance. Hypotheses Life Sci. 2011a;1(1):11-20

49. Loosemore RG. Contralateral translocation of progenitor retinal cells observed on bifurcation of the primordial eye field is predicted by the inversion hypothesis. Hypotheses Life Sci. 2011b;1(2):46-51.

50. Luo L, Flanagan JG. Development of continuous and discrete neurological maps. Neuron. 2007:56:284-300. https://doi.org/10.1016/.j.neuron.2007.10.014

51. MacDonald R, Wilson SW. Pax proteins and eye development. Curr Opin Neurobiol. 1996:6:49-56. https://doi.org/10.1016/S0959-4388(96)80008-0.

52. Marcus $\mathrm{R}$, Mason $C$. The first retinal axon growth in the mouse optic chiasm: axon patterning and the cellular environment. J Neurosci. 1995; 15(10):6389-402

53. Marlow F, Zwartkruis F, Malicki J, Neuhauss SCF, Abbas L, Weaver M, Driever W, Solnica-Krezel L. Functional interactions of genes mediating convergent extension, knypek and trilobite, during the portioning of the eye primordium in zebrafish. Dev Biol. 1998;203:382-99.

54. Martinez-Morales JR, Wittbrodt J. Shaping the vertebrate eye. Curr Opin Genet Dev. 2009;19(5):511-7. https://doi.org/10.1016/j.gde.2009.08.003.

55. Mason CA, Sretavan DW. Glia, neurons, and axon pathfinding during optic chiasm development. Curr Opin Neurobiol. 1997:7:647-53.

56. McLoon SC, Barnes RB. Early differentiation of retinal ganglion cells: an axonal protein expressed by premigratory and migrating retinal ganglion cells. J Neurosci. 1989;9:1424-32.

57. Mogi K, Misawa K, Utsunomiya K, Kawada Y Yamazaki T, Takeuchi S, Toyoizumi R. Optic chiasm in the species of order Clupeiformes, family 
Clupeidae: optic chiasm of Spratelloides gracilis shows an opposite laterality to that of Etrumeus teres. Laterality. 2009;14(5):495-514. https://doi.org/10. 1080/13576500802628160.

58. Nilsson D-E. Eye evolution and its functional basis. Vis Neurosci. 2013;30(12):5-20. https://doi.org/10.1017/S0952523813000035.

59. Nilsson D-E, Pelger S. A pessimistic estimate of the time required for an eye to evolve. Proc R Soc Lond B. 1994;256:53-8.

60. Pacal M, Bremner R. Induction of the ganglion cell differentiation program in human retinal progenitors before cell cycle exit. Dev Dynamics. 2014;243: 712-29. https://doi.org/10.1002/dvdy.24103.

61. Pera EM, Kessel M. Patterning of the chick forebrain anlage by the prechordal plate. Development. 1997;124(20):4153-62.

62. Prasov L, Glaser T. Dynamic expression of ganglion cell markers in retina progenitors during the terminal cell cycle. Mol Cell Neurosci. 2012;50:160-8. https://doi.org/10.1016/j.mcn.2012.05.002.

63. Rebagliati MR, Toyama R, Haffter P, Dawid IB. Cyclops encodes a nodalrelated factor involved in midline signaling. Proc Natl Acad Sci U S A. 1998; 95:9932-7.

64. Rembold M, Loosli F, Adams RJ, Wittbrodt J. Individual cell migration serves as the driving force for optic vesicle evagination. Science. 2006;313:1130-4. https://doi.org/10.1126/science.1127144.

65. Sadler TW. Embryology of neural tube development. Am J Med Genet Part C (Semin. Med. Genetic.). 2005;135C:2-8. https://doi.org/10.1002/ajmg.c.30049.

66. Sampath K, Rubinstein AL, Cheng AM, Liang JO, Fekany K, Solnica-Krezel L, Korzh V, Halpern ME, Wright CV. Induction of zebrafish ventral brain and floor plate requires Cyclops/nodal signaling. Nature. 1998;395:185-9. https:// doi.org/10.1038/26020.

67. Sarnat HB, Netsky MG. Evolution of the nervous system. New York: Oxford Uni Press, Chicago; 1981

68. Schmitt EA, Dowling JE. Early eye morphogenesis in the zebrafish, Brachydanio rerio. J Comp Neurol. 1994;344(4):532-42. https://doi.org/10. 1002/cne.903440404

69. Schoenwolf GC, Alvarez IS. Roles of neuroepithelial cell arrangement and division in shaping of the avian neural plate. Development. 1989;106:427-39.

70. Silver J. Studies on the factors that govern directionality of axonal growth in the embryonic optic nerve and at the chiasm of mice. J Comp Neurol. 1984; 223:238-51.

71. Sinn R, Wittbrodt J. An eye on development. Mech Dev. 2013;130:347-58. https://doi.org/10.1016/.mod.2013.05.001

72. Sretavan DW, Feng L, Pure E, Reichardt LF. Embryonic neurons of the developing optic chiasm express L1 and CD44, cell surface molecules with opposing effects on retinal axon growth. Neuron. 1994;12:957-75.

73. Sretavan DW, Pure E, Siegel MW, Reichardt LF. Disruption of retinal axon ingrowth by ablation of embryonic mouse optic chiasm neurons. Science. 1995;269(5220):98-101. https://doi.org/10.1126/science.7541558.

74. Tawk M, Araya C, Lyons DA, Reugels AM, Girdler GC, Bayley PR, Hyde DR, Tada M, Clarke JDW. A mirror-symmetric cell division that orchestrates neuroepithelial morphogenesis. Nature. 2007:446:797-800. https://doi.org/ 10.1038/nature05722.

75. Van der Brugghen G. Ciderius cooperi gen. nov., sp. nov., the earliest known euphaneropid from the lower Silurian of Scotland. Netherlands J Geosci. 2015;94(3):279-88. https://doi.org/10.1017/njg.2015.18.

76. Varga ZM, Wegner J, Westerfield M. Anterior movement of ventra diencephalic precursor separates the primordial eye field in the neural plate and requires Cyclops. Development. 1999;126:5533-46.

77. Vopalensky P, Pergner J, Liegertova M, Benito-Gutierrez E, Arendt D, Kozmik Z. Molecular analysis of the amphioxus frontal eye unravels the evolutionary origin of the retina and pigment cells of the vertebrate eye. Proc Nat Acad Sci USA. 2012;109(38):15383-8. https://doi.org/10.1073/pnas.1207580109/-/ DCSupplemental.

78. Waid DK, McLoon SC. Immediate differentiation of ganglion cells following mitosis in the developing retina. Neuron. 1995;14:117-24.

79. Walls GL. The vertebrate eye. Bloomfield Hills: Cranbrook Institute of Science; 1942

80. Woo K, Fraser SE. Order and coherence in the fate map in the zebrafish nervous system. Development. 1995;121:2595-609.

\section{Publisher's Note}

Springer Nature remains neutral with regard to jurisdictional claims in published maps and institutional affiliations.

Ready to submit your research? Choose BMC and benefit from:

- fast, convenient online submission

- thorough peer review by experienced researchers in your field

- rapid publication on acceptance

- support for research data, including large and complex data types

- gold Open Access which fosters wider collaboration and increased citations

- maximum visibility for your research: over $100 \mathrm{M}$ website views per year

At BMC, research is always in progress.

Learn more biomedcentral.com/submissions 